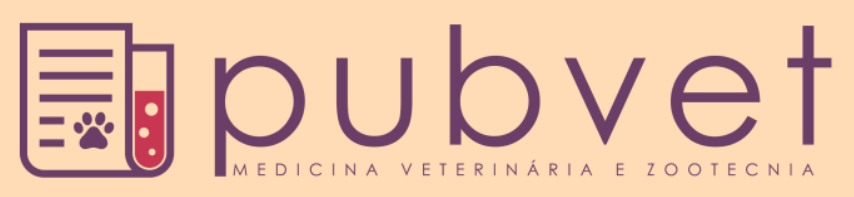

HTTP://DX.DOI.ORG/10.22256/PUBVET.V11N9.901-912

\title{
Nutrição clínica de cães hospitalizados: Revisão
}

\section{Vanessa de Freitas Ferreira ${ }^{1}$, Vera Lúcia Dias da Silva ${ }^{2}$, Henrique Trevizoli Ferraz ${ }^{2 *}$, Priscilla de Carvalho Bueno ${ }^{3}$, Marco Antônio de Oliveira Viu ${ }^{2}$}

${ }^{I}$ Mestranda em Biociência Animal, Regional Jataí, Universidade Federal de Goiás. Jataí - GO, Brasil. Email: vanessafferreira@ yahoo.com.br ${ }^{2}$ Professor(a) do curso de Medicina Veterinária, Regional Jataí, Universidade Federal de Goiás. Jataí - GO, Brasil. Email: veralds12@gmail.com; htferraz@gmail.com, marcoviu@gmail.com

${ }^{3}$ Médica Veterinária. Mineiros - GO, Brasil. Email: priscillacarvalhobueno@gmail.com.

*Autor para correspondência

RESUMO. Conforme demonstram vários estudos, a nutrição de cães hospitalizados é de extrema importância para a recuperação do paciente. Porém, infelizmente, muitas vezes esse aspecto é negligenciado na Medicina Veterinária. Assim, desenvolveu-se este trabalho com o objetivo de esclarecer a importância da implementação de suporte nutricional adequado para cães internados e sua relação com os quadros clínicos mais comumente encontrados na rotina.

Palavras chave: Canino, enteral, metabolismo, parenteral, patologias

\section{Hospitalized dogs clinical nutrition: Review}

ABSTRACT. Several studies show that nutrition of hospitalized dogs is important for patient recovery. However this aspect is often neglected in veterinary medicine. Thus, this work was developed with the purpose of clarifying the importance of the adequate nutritional support implementation for hospitalized dogs and its relation with the most commonly found in the clinical routine.

Keywords: Canine, enteral, metabolism, parenteral, pathologies

\section{Nutrición clínica de perros hospitalizados: Revisión}

REUMEN. Como demuestran varios estudios, la nutrición de perros hospitalizados es de extrema importancia para la recuperación del paciente. Sin embargo, muchas veces ese aspecto es descuidado en la Medicina Veterinaria. Así, se desarrolló este trabajo con el objetivo de esclarecer la importancia de la implementación de suporte nutricional adecuado para perros internados y su relación con los cuadros clínicos más comúnmente encontrados en la rutina.

Palabras clave: Canino, enteral, metabolismo, parenteral, patologías

\section{Introdução}

A maioria dos animais que necessitam de internação em clínicas e hospitais veterinários apresentam quadro clínico grave e alguma alteração sistêmica que pode expor o mesmo a risco de morte, exigindo intervenção imediata do médico veterinário. Para agravar o quadro clínico, anorexia ou desnutrição estão associadas a esses distúrbios sistêmicos em boa parte dos casos ou ainda podem se desenvolver em animais criticamente doentes (Chan and Freeman, 2006).

$\mathrm{Na}$ prática veterinária o suporte nutricional ainda possui prioridade pequena e não faz parte da rotina médica de clínicas e hospitais. É importante lembrar que, durante os períodos de privação de nutrientes, um paciente doente ou traumatizado, preferencialmente, irá catabolizar massa magra quando $\mathrm{o}$ fornecimento de calorias for 
insuficiente. Isto devido à maior liberação de mediadores endógenos como hormônios do estresse e citocinas, diferentemente do que ocorre com um animal saudável privado de alimento, no qual a energia é derivada de fontes de gordura armazenada. A mobilização de aminoácidos afeta negativamente a função imunitária, cicatrização de feridas e o estado geral do animal (Brunetto et al., 2009).

São vários fatores que promovem a ingestão calórica inadequada: perda de apetite, inabilidade para comer ou tolerar a alimentação e disfunções no trato gastrintestinal, sinais clínicos que acompanham muitos processos patológicos. Nesses pacientes a desnutrição pode ocorrer rapidamente e o suporte nutricional deverá ser instituído o quanto antes, seja pela via entérica, quando o animal está apto a receber alimento, ou pela via parentérica, se a ingestão oral não for tolerada ou for inadequada no momento (Chan, 2009).

Brunetto et al. (2010) demonstraram que animais que receberam nutrição adequada durante o período de internação apresentaram maior índice de alta em relação aos animais que não receberam , sendo que o suporte nutricional intensivo mostrou-se eficiente em infundir nutrientes ao animal. O mais adequado é que a nutrição ocorra da forma mais fisiológica possível, sendo que o primeiro passo a ser adotado é estimular a ingestão natural (Armstrong and Lippert, 1988). Em alguns casos, oferecer alimentos aquecidos e mais palatáveis é suficiente para garantir a ingestão das calorias necessárias (Nelson and Couto, 2015).

Caso haja fracasso na tentativa de alimentar o animal de forma natural ou a ingestão voluntária esteja contra indicada, deve-se partir para o suporte nutricional enteral através de sonda nasoesofágica, gástrica ou duodenal, de acordo com o estado clínico do paciente (Carciofi, 2008). Já foram estabelecidas algumas características para identificar caninos candidatos ao suporte nutricional (Armstrong and Lippert, 1988); porém a falta de estudos mais precisos sobre as necessidades nutricionais de cães enfermos em diferentes estágios da doença torna a nutrição clínica de pacientes críticos um grande desafio (Brunetto et al., 2010).

Apesar da existência de vários protocolos e técnicas de nutrição clínica, existem alguns obstáculos que dificultam sua execução como, por exemplo, pacientes com distúrbios gastrintestinais que não toleram nutrição enteral (NE). A realização de nutrição parenteral (NP) também possui grandes empecilhos, tais como elevado custo de realização e manutenção, dependência de equipamentos específicos e disponibilidade de realização de vários exames bioquímicos (Brunetto et al., 2010).

Diante do exposto, o objetivo com este trabalho é esclarecer a importância da implementação de suporte nutricional para cães hospitalizados e sua relação com os quadros clínicos mais comuns encontrados na rotina do médico veterinário.

\section{Alterações metabólicas no animal enfermo}

Cães enfermos apresentam alterações metabólicas únicas que predispõem grande risco de desnutrição e seus malefícios. Estes incluem comprometimento da imunocompetência, má cicatrização, maiores incidência de deiscência de feridas, predisposição à ocorrência de infecção de feridas e septicemia, fraqueza muscular (cardíaca, lisa e esquelética), desenvolvimento de insuficiência orgânica e óbito (Fontoura et al., 2006). De acordo com Lewis et al. (2012), a septicemia representa a principal causa de morte em pacientes veterinários criticamente doentes.

Ocorrem respostas diferentes em animais enfermos e em animais saudáveis mediante ingestão nutricional inadequada (Chan, 2009). O organismo do animal saudável consegue se adaptar bem a períodos curtos e longos de jejum, utilizando suas reservas de carboidratos, lipídeos e proteínas por mecanismos que diminuem o gasto energético e preservam as proteínas. A reação ao jejum está diretamente relacionada às reservas energéticas, à duração do jejum e a outros fatores que provoquem estresse adicional. Os mecanismos compreendem diminuição da secreção de insulina e aumento da secreção de glucagon e catecolamina, resultando em glicogenólise e lipólise, responsáveis por mobilizar carboidratos e lipídeos para suprir o gasto energético em períodos relativamente curtos de jejum. Em períodos de jejum superiores a 72 horas a insulina se encontra ainda mais diminuída e os níveis de glicogênio já não são suficientes para suprir a demanda energética do organismo, sendo, portanto, requeridos aminoácidos musculares para a gliconeogênese. Na tentativa de reduzir a degradação muscular ocorre diminuição da taxa metabólica e da demanda de glicose (Lehninger, 2006).

O organismo pode armazenar glicose na forma de glicogênio no fígado e músculo esquelético, 
sendo que quando ocorre mobilização de glicose a partir dessa reserva o processo é denominado glicogenólise. Isso disponibiliza glicose para oxidação, liberando energia para o organismo. Esta também pode se armazenada na forma de triglicerídeos e ácidos graxos, uma forma concentrada de armazenamento de gordura por possuir o dobro do valor calórico por grama, quando comparado aos carboidratos ou aminoácidos. Em períodos prolongados de subnutrição os triglicerídeos são mobilizados do tecido adiposo pela ação da enzima lipase, estimulada pela falta de insulina circulante. Uma vez no sangue, os ácidos graxos ligam-se à albumina e são transportados aos tecidos onde podem sofrer oxidação completa para produção de energia ou seguir a via de esterificação, resultando na produção de triglicerídeos ou formação de corpos cetônicos. Os corpos cetônicos afetam a homeostase de fontes de energia nos tecidos periféricos e podem atuar como substituto da glicose, conservando a glicemia e diminuindo a necessidade de neoglicogênese (Cunningham, 2011).

O metabolismo do animal enfermo em jejum, associado ou não à inapetência ou anorexia, não consegue se adaptar normalmente e economizar proteína muscular devido aos efeitos neuroendócrinos e de citocinas em resposta ao traumatismo, septicemia e doenças graves. Ao contrário do que ocorre em animais saudáveis em jejum, naqueles gravemente doentes ocorre aumento do metabolismo e do catabolismo proteico, além de hiperglicemia para suprir a demanda de aminoácidos requeridos para reparar tecidos e para a rota de gliconeogênese (Lehninger, 2006). Situações como cirurgias, politraumatismos, grandes queimaduras e neoplasias aumentam o gasto de calorias oriundas de proteínas e outros substratos para reparação dos danos, aumentando a necessidade de nutrientes para realizar homeostase e promover a recuperação do paciente (Dudrick, 2009). Animais criticamente doentes respondem ao estresse com hipermetabolismo, síntese inadequada de proteínas e catabolismo. Isso acarreta um desarranjo metabólico que requer suporte nutricional para frear a perda de massa magra, melhorar as respostas imunológicas e diminuir índices de morbidade e mortalidade (Codner, 2012).

Se o estado hipermetabólico continuar sem intervenção, pode ocorrer imunossupressão, esgotamento de nutrientes em nível tecidual e celular, falência de órgãos e, consequentemente, óbito do paciente (Liu et al., 2012). Vários efeitos negativos ocorrem devido à perda progressiva de massa magra na cicatrização de feridas, função imunitária e força esquelética e respiratória, piorando o prognóstico do paciente hospitalizado (Chan and Freeman, 2006). A demora de três dias em iniciar a NE, a doença crítica e o estresse oxidativo, conduzem a uma redução no tamanho da vilosidade e na profundidade da cripta, assim como no aumento na permeabilidade intestinal (o que permite o escape de bactérias Gram negativas), ulceração e atrofia da mucosa (Chan, 2009). A presença de nutrientes no lúmen intestinal pode prevenir estes efeitos deletérios (Nguyen et al., 2012)

\section{Plano nutricional}

Na década de 1950 a maioria dos clínicos estava ciente do impacto negativo da fome sobre a morbidade e a mortalidade, mas poucos entenderam a necessidade de suporte nutricional adequado para pacientes desnutridos (Dudrick, 2009). Mesmo nos dias atuais, com todas as informações sobre metabolismo, o suporte nutricional não recebe dos médicos veterinários importância adequada. Silva (2009) verificou, por de questionários feitos aos profissionais veterinários em Portugal, que 25\% conheciam as técnicas de suporte nutricional, 25\% conheciam alguns métodos e que metade deles não conhecia nenhum. Informação alarmante devido à grande importância que o fornecimento adequado de nutrientes possui. Holahan et al. (2010) ressaltaram a importância do fornecimento adequado de alimentação na recuperação de pacientes criticamente enfermos e, para isso, o conhecimento do médico veterinário acerca das técnicas empregadas é essencial.

Rabelo et al. (2012) definiram suporte nutricional como sendo o fornecimento, por via enteral e/ou parenteral, de nutrientes como proteínas, carboidratos, lipídeos, vitaminas e minerais, recomendando que o momento ideal de iniciá-lo é logo após a estabilização dos parâmetros hemodinâmico, eletrolítico e ácidobásico do paciente, antes mesmo do desenvolvimento da desnutrição ou logo que a mesma seja diagnosticada, com o objetivo de minimizar o tempo de internação ou óbito. (Chan, 2009) relatou que o consumo inadequado de alimentos por tempo prolongado pode levar à desnutrição e pode estar associada ao metabolismo deficiente, imunossupressão, cicatrização 
comprometida e aumento de morbidade e mortalidade.

Liu et al. (2012) relataram que o suporte nutricional dentro de 24 horas após a cirurgia de cães com peritonite séptica esteve associado à redução do tempo de internação. $O$ período de tempo ótimo ou atraso aceitável antes do início do suporte nutricional não foi definido em cães em estado crítico e pode variar de acordo com o processo patológico e com as várias vias utilizadas para fornecer a nutrição. Kawasaki et al. (2009) defendem que a NE em pacientes cirúrgicos deve ser iniciada imediatamente após a realização do procedimento, caso o trato gastrointestinal esteja disponível.

A função primordial do suporte nutricional para cães hospitalizados não é promover ganho de peso, mas diminuir a intensa perda de musculatura que ocorre nesses animais, suprindo as deficiências de nutrientes que atuam como catalisadores da cura da doença primária, além da reversão do quadro nutricional (Chan, 2009). Segundo Carciofi (2008) são pontos importantes para o desenvolvimento e aplicação de um protocolo nutricional: avaliar a condição nutricional inicial do paciente; estimar a proporção e relação entre as fontes de energia do alimento; estimar as necessidades calóricas e de outros nutrientes para cada paciente; avaliar a melhor dieta e via de administração de acordo com a apresentação clínica do cão; observar a reação do organismo e fazer ajustes quando necessário; e planejar a transição para dieta e alimentação de manutenção.

É importante considerar alguns fatores no planejamento nutricional, incluindo energia, proteínas, carboidratos, aminoácidos e ácidos graxos específicos, eletrólitos, antioxidantes, conteúdo prebiótico e probiótico, controle de peso e controle de doença gastrintestinal, além do acompanhamento e reavaliação do plano nutricional, estipulando mudanças quando necessário (Campbell, 2007). De acordo Oliveira et al. (2008), a avaliação nutricional confiável deve considerar informações fornecidas pelo proprietário, que muitas vezes não são precisas, histórico e exame clínico do animal.

Existem alguns passos básicos para calcular a necessidade energética diária (expressa em $\mathrm{kcal} /$ dia) de um animal em estado crítico, o chamado requerimento energético de manutenção (REM). Primeiramente deve-se calcular a energia que um animal saudável em repouso necessita, conhecida como gasto de energia em repouso (GER) ou requerimento energético basal (REB). Para o cálculo do REB em cães de 2,0 a 25,0 kg utiliza-se a fórmula: $30 \mathrm{x}$ (peso em $\mathrm{kg}$ ) +70 . Para animais com menos de 2,0 ou mais de $25,0 \mathrm{~kg}$, o cálculo deve ser feito utilizando-se a expressão: 70 $\mathrm{x}$ (peso em kg) ${ }^{0,75}$. Posteriormente, para o cálculo do REM em cães enfermos, deve-se multiplicar o REB pelo fator de ajuste energético de acordo com a injúria que acomete o paciente. Os principais fatores de ajuste são: 1,25 para repouso em gaiola; 1,3 para o pós-cirúrgico; 1,5 para traumatismos; 1,7 para sepse; e 2,0 para queimaduras graves (Nelson and Couto, 2015).

Os animais que sofrem alguma injúria ou doença possuem necessidade energética muito maior do que aqueles em repouso. A taxa metabólica de animais em pós-operatório aumenta de $25 \%$ a $35 \%$ em relação ao nível de repouso. No trauma leve, esse aumento na necessidade energética é de $35 \%$ a $50 \%$ e, em pacientes septicêmicos, $50 \%$ a $70 \%$ a mais de energia pode ser requerida (Walton et al., 1996). Adicionalmente, Brunetto et al. (2010) observaram que a taxa de alta e de óbito de animais internados está diretamente relacionada com a ingestão do REM, de tal maneira que a alta foi maior e os óbitos menos frequentes em animais com consumo calórico mais próximo do seu REM.

\section{Estimulantes do apetite}

Espera-se que a nutrição ocorra da forma mais fisiológica possível. Portanto, diante de um paciente que não apresenta ingestão espontânea de alimentos, o primeiro passo a ser adotado é estimular a ingestão natural (Armstrong and Lippert, 1988). Em alguns casos oferecer alimentos palatáveis e aquecidos é suficiente para que o animal consuma a quantidade necessária de nutrientes e calorias (Nelson and Couto, 2015). O simples fato de dar alta ao paciente e a presença do proprietário também podem estimular o animal a voltar a se alimentar espontaneamente, já que eles manifestam comportamento de estresse em ambientes hospitalares, afetando negativamente a ingestão de alimentos mesmo em animais saudáveis (Hekman et al., 2012).

Caso haja falha na tentativa de estimular o animal a se alimentar espontaneamente e não existindo nenhuma contraindicação, a estimulação do apetite pela utilização de fármacos é uma opção. Alguns derivados benzodiazepínicos e corticosteróides têm sido utilizados com sucesso, porém essas drogas podem provocar efeitos 
indesejados (Oliveira et al., 2008) Diazepam e oxazepam proporcionam efeito imediato sobre o apetite, mas seu efeito é de curta duração. A prednisolona pode ser usada por curtos períodos com a finalidade de estimular o apetite, mas seus efeitos adversos podem ser potencialmente significativos (Fontoura et al., 2006). Os principais fármacos estimulantes de apetite, sua posologia e efeitos adversos estão resumidos na tabela a seguir.

Tabela 1. Principais estimulantes do apetite, dosagem e efeitos colaterais

\begin{tabular}{llll}
\hline Fármaco & Classe farmacológica & Dosagem & Efeitos colaterais potenciais \\
Diazepam & Benzodiazepínico & $0,1-0,2 \mathrm{mg} / \mathrm{kg}, \mathrm{VO}$, a cada 12-24h $\begin{array}{l}\text { Alimentação não proposital, sedação, } \\
\text { encefalopatia hepática, } \\
\text { hepática idiossincrásica. }\end{array}$ \\
$\begin{array}{lll}\text { Oxazepam } \\
\text { Ciproeptadina }\end{array}$ & $\begin{array}{l}\text { Benzodiazepínico } \\
\text { da serotonina }\end{array}$ & $0,3-0,4 \mathrm{mg} / \mathrm{kg}, \mathrm{VO}$, a cada 12-24h Como o Diazepam \\
Cianocobalamina & Vitamina hidrossolúvel & $1.000 \mu \mathrm{g}, \mathrm{SC}$ ou IV & Excitabilidade, agressão, vômitos. \\
Boldenona & Esteroide & $5,0 \mathrm{mg}, \mathrm{SC}$ ou IM, a cada 24h & $\begin{array}{l}\text { Início tardio de atividade, dor muscular } \\
\text { no local da injeção. }\end{array}$ \\
Estanazolol & Esteroide & $5,0-20,0 \mathrm{mg}, \mathrm{VO}$, a cada 12-24h & Início tardio de atividade \\
Nandrolona & Esteroide & $1,0-2,0 \mathrm{mg}, \mathrm{VO}$, a cada 12-24h & Incomum \\
Prednisolona & Glicocorticoide & $5,0 \mathrm{mg} / \mathrm{kg}, \mathrm{IM}$, semanalmente & $\begin{array}{l}\text { Poliúria, polidipsia, menor cicatrização } \\
\text { de feridas. }\end{array}$ \\
\hline
\end{tabular}

Fonte: Adaptado de Fontoura et al. (2006).

A estimulação química do apetite deve ser utilizada apenas para motivar o início espontâneo da alimentação, devendo a ingestão da dieta prosseguir sem o uso contínuo desses fármacos para essa finalidade (Fontoura et al., 2006). Caso todas essas alternativas falhem e o animal continue inapetente, o próximo passo é a aplicação de técnicas mais precisas de suporte nutricional, como a NE e a NP, cuja escolha mais adequada depende do estado clínico e da patologia do paciente (Oliveira et al., 2008, Chan, 2009).

\section{Nutrição enteral (NE)}

A NE consiste no fornecimento de nutrientes na luz do trato gastrintestinal pela boca, sondas ou ostomias, possibilitando a manutenção ou recuperação do estado nutricional do paciente (Brunetto et al., 2009, Codner, 2012).Trata-se da técnica mais próxima do fisiológico por utilizar o trato digestório e, sempre que possível, o suporte nutricional enteral é preferível ao parenteral (Armstrong and Lippert, 1988).

A presença de nutrientes no lúmen do intestino possibilita a viabilidade e nutrição das próprias células intestinais, evita a atrofia da mucosa, melhora a capacidade de absorver nutrientes e favorece a defesa contra a penetração de antígenos e a translocação bacteriana (Brunetto et al., 2009). De acordo com Kawasaki et al. (2009), a NE contribuiu para a recuperação gastrintestinal e para a manutenção da condição nutricional do paciente hospitalizado. Sinais clínicos como vômitos, regurgitação ou diarreia devem ser interpretados com cautela, uma vez que é impossível saber se esses problemas ocorreram devido ao processo patológico presente ou pela administração da NE (Campbell et al., 2010).

Os dois métodos mais comuns de fornecimento de NE em animais e humanos são infusão contínua ou em bolus intermitente. Cães criticamente doentes podem ser alimentados com êxito tanto com infusão contínua quanto intermitente de NE, com poucas complicações. Pacientes críticos com disfunção na motilidade gastrintestinal toleram melhor a infusão contínua de alimentação, embora a alimentação intermitente em bolus represente um método mais fisiológico de fornecer alimento. Conforme demonstrado na Tabela 2, pacientes alimentados intermitentemente alcançaram a meta nutricional mais rápido do que aqueles alimentados continuamente (Holahan et al., 2010).

\section{Sonda naso-esofágica}

A NE fornecida por sonda naso-esofágica é o mais indicado quando o suporte nutricional não ultrapassar uma semana. A sonda não pode alcançar o estômago e os nutrientes são entregues na porção distal do esôfago. Essa técnica é de 
custo baixo e fácil execução, dispensando a necessidade de anestesia geral e sendo bem tolerada pelo paciente. Contudo, a sonda nasoesofágica possui pequeno calibre e permite apenas a administração de dietas líquidas, o que se torna um obstáculo para o suprimento proteico e calórico de pacientes enfermos. Por isso o alimento fornecido deve ser úmido $\mathrm{e}$ hipercalórico, diluído em água (Brunetto et al., 2009, Chan, 2009).

Tabela 2. Protocolo de NE contínua e intermitente para cães hospitalizados

\begin{tabular}{|c|c|c|}
\hline Tempo & NE Contínua & NE Intermitente \\
\hline $0-24$ horas & $\begin{array}{l}1 / 3 \text { do REB dividido em } 24 \text { horas e } \\
\text { fornecido em X mL/h }\end{array}$ & $\begin{array}{l}\text { (1/3 REB) dividido em } 6 \text { refeições, } \\
\text { fornecidas durante } 30 \text { minutos a cada } 4 \\
\text { horas. }\end{array}$ \\
\hline 24-48 horas & $\begin{array}{l}2 / 3 \text { do REB dividido em } 24 \text { horas e } \\
\text { fornecido em } X \mathrm{~mL} / \mathrm{h}\end{array}$ & $\begin{array}{l}(2 / 3 \mathrm{REB}) \text { dividido em } 6 \text { refeições, } \\
\text { fornecidas durante } 30 \text { minutos a cada } 4 \\
\text { horas. }\end{array}$ \\
\hline $\begin{array}{l}48-72 \text { horas, continuar até alcançar o } \\
\text { objetivo. }\end{array}$ & $\begin{array}{l}3 / 3 \text { do REB dividido em } 24 \text { horas e } \\
\text { fornecido em } X \mathrm{~mL} / \mathrm{h}\end{array}$ & $\begin{array}{l}(3 / 3 \text { REB) dividido em } 6 \text { refeições, } \\
\text { fornecidas durante } 30 \text { minutos a cada } 4 \\
\text { horas. }\end{array}$ \\
\hline
\end{tabular}

Fonte: Adaptado de Holahan et al. (2010).

Antes da introdução da sonda é necessário estimar o comprimento que será introduzido, desde o plano nasal até o sétimo espaço intercostal, o que garantirá que a sonda alcance o esôfago e não penetre no estômago. Essa medida é marcada geralmente com esparadrapo aderido à sonda. Deve-se lubrificar a extremidade da sonda com lidocaína 5\% e manter a cabeça do animal em posição anatômica. A sonda deve ser introduzida na narina pela face ventrolateral e seguir em direção caudoventral e medial. O septo mediano encontra-se a aproximadamente $3,0 \mathrm{~cm}$ de profundidade na narina e, caso haja dificuldade em prosseguir, as narinas externas devem ser empurradas dorsalmente, facilitando a abertura do meato ventral. Injetar $5,0 \mathrm{~mL}$ de solução fisiológica na sonda é útil para confirmar a localização. Ausência de tosse ou espirro indica posição esofágica. Emergir a extremidade livre da sonda em solução fisiológica também auxilia na confirmação do posicionamento correto da sonda, desde que não haja formação de bolhas de ar. Radiografia também pode ser realizada para auxiliar na confirmação da posição da sonda, sendo uma opção mais segura, porém, mais onerosa. A sonda pode ser fixada com cola de cianocrilato e o animal deve utilizar colar elizabetano para protegê-la (Brunetto et al., 2009, Nelson and Couto, 2015).

\section{Sonda esofágica}

A NE via sonda esofágica tem sido utilizada com sucesso em animais que não toleram ou não podem ingerir alimento voluntariamente. Mansfield et al. (2011) verificaram que a NE por meio de esofagostomia, em cães portadores de pancreatite grave e que não estavam aptos a ingerir voluntariamente os nutrientes, resultou em menos complicações do que o uso da NP. Em humanos, o suporte nutricional enteral por meio de tubo de alimentação tem sido eficiente para pacientes disfágicos vítimas de acidente vascular cerebral (Kang et al., 2010).

A sonda esofágica é colocada através de esofagostomia, um procedimento simples de ser executado que minimiza o desconforto provocado ao animal, podendo permanecer por semanas ou meses se necessário. Essa técnica permite que o paciente se alimente e ingira água normalmente. Também possui fácil manejo, o que permite a cooperação do proprietário e minimiza custos com internação em clínicas e hospitais veterinários (Brunetto et al., 2009). Para Chan (2009), a sonda esofágica é o tubo mais útil e eficaz disponível e deve ser considerada na maioria dos pacientes dentro da unidade de cuidados intensivos que estão em risco de desnutrição. Adicionalmente, foi verificado que esta sonda possui maior eficiência em fornecer nutrientes que a nasal, com consumo médio de calorias semelhantes aos animais que se alimentavam voluntariamente (Brunetto et al., 2010). A sonda esofágica possui maior diâmetro que a sonda naso-esofágica, o que permite a administração de volumes maiores e mais consistentes de alimentos. $\mathrm{O}$ início do fornecimento de alimento deve ser cerca de duas horas após o procedimento cirúrgico, recomendando-se administrar o REM. A adaptação é importantíssima, especialmente em se tratando de animais anoréticos, devido ao risco eminente de desenvolverem síndrome da realimentação ou distúrbios digestivos (Brunetto et al., 2009, Silva, 2009). 
O alimento deve ser preparado antes de ser administrado. Umedecer, triturar e coar é indicado para facilitar a digestão. Deve sempre ser oferecido em bolus com seringas, divididos em seis refeições diárias que somadas oferecem a necessidade nutricional do paciente. A limpeza da sonda com água é importante e garante o sucesso do procedimento. A quantidade de água fornecida ao animal $(50$ a $70 \mathrm{~mL} / \mathrm{kg}$ para animais normohidratados) deve ser descontada da água utilizada na higienização e na umidificação do alimento (Chan and Freeman, 2006, Oliveira et al., 2008, Brunetto et al., 2009).

\section{Sonda gástrica}

A sonda no estômago para fornecimento de nutrição é considerada uma via segura, favorecendo digestão adequada (Brunetto et al., 2010). É indicada para período de suporte enteral de semanas e consiste numa forma eficiente de fornecer nutrientes a pacientes acometidos por doenças orofaringeanas, distúrbios esofágicos, lipidose hepática e outras enfermidades debilitantes. Entretanto, esse tipo de suporte enteral é contraindicado para período de uso inferior a cinco dias ou em casos onde o paciente apresente vômitos persistentes, desordens gastrentéricas, ascite, peritonite e pancreatite. A facilidade de manejar a sonda, de reiniciar a alimentação oral e a boa adaptação do animal ao seu uso proporcionam maior adesão dos proprietários ao suporte instituído. Além disso, o maior diâmetro da sonda gástrica em relação à sonda esofágica permite a administração de alimentos mais consistentes (Fontoura et al., 2006, Brunetto et al., 2009).

A grande desvantagem do uso da sonda de gastrotomia é a necessidade de anestesia para sua instalação, a possibilidade do desenvolvimento de peritonite e o aparecimento de sinais clínicos indesejados como vômito e diarreia, além da dificuldade de encontrar no mercado os tubos específicos utilizados nessa técnica. Os cuidados com a administração, os cálculos e os tipos de dietas empregadas são semelhantes àqueles usados para esofagostomia (Brunetto et al., 2009).

\section{Sonda intestinal}

A sonda intestinal ou de jejunostomia é indicada quanto todos os órgãos do sistema digestório posicionados anteriormente ao jejuno devem ser evitados como, exemplo, em caso de ressecção de parte significativa da parede do estômago, pancreatite grave e pancreatectomia, cirurgia hepatobiliar, obstrução gastrintestinal proximal, neoplasia, cirurgia gastrintestinal extensa, coma e distúrbios de motilidade esofágica. Está contraindicada quando houver obstrução do segmento intestinal posterior ao local de inserção do tubo e em caso de peritonite. Essa técnica minimiza os riscos de refluxo gastroesofágico presente nas técnicas anteriormente citadas (Oliveira et al., 2008, Brunetto et al., 2009, Chan, 2009).

A colocação de sondas de enterotomia geralmente requer a realização de laparotomia. Seu diâmetro reduzido exige a administração de dietas líquidas facilmente infundidas, respeitando o resultado do cálculo de necessidade energética obtido. No primeiro dia deve-se fornecer dieta com metade da concentração calculada e duas vezes mais devagar. Para o segundo dia a taxa de administração deve ser a calculada e concentração continua duas vezes menor. Somente no terceiro dia todas as taxas calculadas devem ser administradas ao paciente. Caso ocorra diarreia, fibras podem ser adicionas à dieta (Nelson and Couto, 2015).

É adequado deixar a sonda por sete a dez dias para a formação de aderências e impedir que extravase conteúdo intestinal, sendo o fornecimento da dieta iniciado após 24 horas do procedimento cirúrgico. Por ser entregue após o estômago, é recomendável a utilização de dietas pré-digeridas. Com a utilização de dietas para sonda gástrica podem ocorrer efeitos adversos como diarreia, flatulência e desconforto abdominal, devido à ausência da ação do ácido clorídrico, proteases e lipases gástricas sobre o alimento. $\mathrm{O}$ intestino não suporta grandes volumes de alimento e, por isso, no suporte nutricional via enterotomia a dieta deve ser infundida continuamente com o auxílio de um equipo e, por isso, é uma técnica que requer hospitalização e monitoração frequente (Brunetto et al., 2009, Nelson and Couto, 2015).

\section{Nutrição parenteral}

Na década de 1960 o dogma que predominava sobre a NP era de que a alimentação inteiramente por acesso venoso era impossível e, mesmo que fosse possível, seria impraticável. Ainda que praticável, seria inviável. Aos poucos o desenvolvimento de técnicas adequadas e os estudos metabólicos e nutricionais permitiram que esse meio de fornecimento de nutrientes, considerado tão utópico, se tornasse realidade 
(Dudrick, 2009). A NP é mais cara do que a NE e tem seu uso restrito ao ambiente hospitalar devido à necessidade da implantação de cateter colocado em condições assépticas (Chan, 2009). Devido aos efeitos adversos e às complicações técnicas que envolvem a NP, essa forma de suporte nutricional deve ser reservada para cães incapazes de consumir quantidades adequadas ou que não toleram nutrientes entéricos por um período de quatro a cinco dias de anorexia. NP é tipicamente uma mistura de emulsão de gordura, dextrose e solução de aminoácidos. Os componentes são adquiridos separadamente e a solução preparada de forma asséptica. Em muitos casos eletrólitos, vitaminas do complexo B e alguns minerais são adicionadas. Essa solução deve ser balanceada de acordo com a necessidade de cada paciente, o que torna a sua utilização, na prática, difícil. Deve ser administrada, inicialmente, para atender a uma fração da necessidade do animal, sendo aumentada gradualmente com base na resposta do paciente (Carciofi (Carciofi et al., 2009, Chan, 2009, Queau et al., 2011, Mansfield et al., 2011).

As principais indicações para o uso desta terapia são a obstrução gastrintestinal, hipomotilidade gastro-entérica, má absorção, diarreias profusas, vômitos severos, período pósoperatório de determinados procedimentos cirúrgicos do trato gastrintestinal, pancreatite, peritonite, hepatite, coma, inconsciência ou deficiências neurológicas severas, ocasiões em que a colocação de tubos não é possível ou em outras circunstâncias individuais (Chan et al., 2002). A NP é classificada como total (NPT) quando fornece $100 \%$ das necessidades de nutrientes e calorias ou como parcial (NPP), ao fornecer apenas uma fração das necessidades nutricionais diárias de um animal (Queau et al., 2011). A NP permite a recuperação de pacientes em estado crítico por fornecer calorias para atividades fundamentais na recuperação do animal, como o sistema imune e a cicatrização (González Domínguez et al., 2008), sendo de extrema importância estabelecer o equilíbrio ácido básico e hidratar o paciente antes de iniciar o suporte de NP, pois podem desenvolverem-se transtornos metabólicos graves.

\section{Carboidratos}

Várias fontes de energia podem ser aplicadas para uso em NP, tais como glicose, dextrose, galactose, entre outras. Contudo, a primeira é a fonte de carboidrato mais utilizada em soluções de NP e se encontra em várias concentrações diferentes, variando entre $5 \%$ e $70 \%$. A mais utilizada nas formulações é a concentração de $50 \%$, por fornecer $1,7 \mathrm{kcal} / \mathrm{mL}$. Soluções com $5 \%$ de concentração são aplicadas para hidratação e não servem para fornecer energia devido à alta diluição desse açúcar. A velocidade de infusão tem efeito direto sobre o risco de desenvolver desequilíbrio metabólico. A glicose administrada intravenosa pode seguir diferentes rotas metabólicas, sendo que a mais desejada é a oxidação, fornecendo mais energia para o organismo. Contudo, a glicose também pode seguir por outras rotas não oxidadivas, incorporando-se ao glicogênio de reserva ou seguindo pela rota anaeróbica, o que produz ácido lático, aumentando os riscos metabólicos (Carciofi et al., 2009).

Utilizar glicose como fonte única de caloria não proteica é barato, porém não recomendado porque muitos pacientes criticamente doentes apresentam resistência insulínica periférica, que pode ocasionar hiperglicemia, glicosúria, poliúria, desidratação e acidose. Além disso, a glicose não é eficiente em limitar a lipólise e mobilização de proteína muscular em cães, sendo preferível mesclar o fornecimento de energia com glicose e lipídeos. Pacientes diabéticos e hiperglicêmicos devem ter a maior parte das calorias fornecidas oriundas de aminoácidos e peptídeos e serem monitorados frequentemente durante o suporte nutricional, além de ajustar, conforme a necessidade, a insulinoterapia. Para cães hiporéticos a distribuição ideal de calorias de origem não proteica é de 50 a $70 \%$ provenientes de carboidrato e de 30 a $50 \%$ provenientes de lipídeos. Em caso de anorexia, a distribuição passa a ser de $40 \%$ de carboidratos e $60 \%$ de lipídeos, devido à adaptação do organismo para utilizar lipídeos como fonte de energia durante períodos prolongados de jejum (Carciofi et al., 2009).

\section{Lipídeos}

Os lipídeos são utilizados como fonte de ácidos graxos e energia (Oliveira et al., 2008). Estão disponíveis para serem usados em NP na forma de emulsões lipídicas constituídas, principalmente, por óleo de soja ou de cártamo, glicerina, ácidos graxos essenciais e gema de ovo como emulsificante. Esses ingredientes fornecem, predominantemente, ácidos graxos polinsaturados de cadeia longa e triglicérides (Chan and Freeman, 2006). 
Após infusão endovenosa, a emulsão lipídica segue via metabólica semelhante à dos quilomícrons resultantes da ingestão oral de gordura. Tem-se verificado a tendência de evitar o uso de emulsão rica em ácido graxo poliinsaturado do tipo n-6 devido ao risco de imunossupressão. Para evitar essa possibilidade, a infusão de lipídeos em cães deve ser limitada em 2,0 g/kg/dia. Em cães hipertriglicêmicos é necessário reduzir ainda mais a dose desse composto ou até mesmo evitar seu uso. Uma grande vantagem é que as soluções lipídicas possuem alta densidade energética (aproximadamente 2,0 $\mathrm{kcal} / \mathrm{mL}$ em solução a 20\%). Contudo, algumas dessas soluções favorecem o crescimento bacteriano e aumentam o risco de septicemia. Seu uso é mais efetivo em fornecer as calorias necessárias se comparado com a glicose isolada, porém apresentam custo elevado (Carciofi et al., 2009).

\section{Aminoácidos}

Consistem em soluções cristalinas que são fontes de proteínas e nitrogênio (Oliveira et al., 2008). A maior parte das soluções disponíveis apresentam todos os aminoácidos essenciais para cães e gatos, exceto a taurina, que é importantíssima para os felinos. Algumas formulações também não apresentam arginina, o que deve ser verificado no momento da escolha do produto. De qualquer forma, para evitar erros, deve-se verificar a presença ou ausência de todos os aminoácidos essenciais: arginina, histidina, isoleucina, leucina, metionina, fenilalanina, treonina, triptofano, valina e lisina (Carciofi et al., 2009). É importante fornecer aminoácidos para manutenção do balanço nitrogenado positivo e reposição da massa magra, o que pode definir a recuperação do paciente crítico. As soluções estão disponíveis em diferentes concentrações, de 3,5\% a $15 \%$, sendo que a mais utilizada é a de $8,5 \%$, contendo ou não eletrólitos. Visando facilidade, geralmente, opta-se por utilizar soluções que já possuem eletrólitos em sua composição (Chan and Freeman, 2006, Carciofi et al., 2009). As soluções de aminoácidos sem eletrólitos são utilizadas em animais que possuem algum distúrbio eletrolítico, de modo que possa ser corrigido individualmente (Chan and Freeman, 2006).

A infusão de aminoácidos deve ser diminuída em pacientes com alterações renais ou encefalopatia hepática e aumentada em enfermidades que provoquem perdas profundas e contínuas de proteína como, por exemplo, enteropatias ou peritonite (Lehninger, 2006, Liu et al., 2012, Nguyen et al., 2012).

Dois aminoácidos que merecem destaque em nutrição clínica de cães são a $\operatorname{arginina~e~a~}$ glutamina. A arginina é um aminoácido essencial para cães e gatos, participando de várias reações metabólicas. Constitui o substrato para a síntese de óxido nítrico, importante para a homeostase do corpo por ser um regulador do endotélio vascular, atua na fisiologia dos macrófagos e nas respostas inflamatórias, influencia no crescimento e diferenciação celular, além de participar do metabolismo do nitrogênio e energia. Dietas que excluem esse aminoácido podem predispor $\mathrm{o}$ paciente a desenvolver hiperamonemia e não devem ser adotadas para cães (Silva, 2009).

A glutamina, um aminoácido não essencial para cães e que pode ser sintetizado pelo organismo animal desde que haja nutrientes suficientes, pode ter seus níveis séricos seriamente reduzidos em situações como trauma, septicemia e câncer, o que caracteriza necessidade de reposição. Nutriente chave em muitos processos metabólicos, a glutamina atua na síntese proteica, gliconeogênese, homeostasia e biossíntese de ácidos nucleicos. Foi demostrado que, em animais e no homem, a suplementação da NP com glutamina pode evitar atrofia intestinal relacionada ao trauma. Além disso, a permeabilidade intestinal pode ser mantida e as microvilosidades preservadas com a adição desse aminoácido. Parte da glutamina é convertida em alanina e utilizada na gliconeogênese pelo fígado. Outras células de turnover elevado também utilizam a glutamina como fonte principal de nitrogênio e carbono sendo que, em caso de hipermetabolismo, ocorre intensa mobilização da glutamina. Portanto, a suplementação de glutamina pode favorecer a redução das taxas de morbidade e mortalidade (Carciofi et al., 2009).

\section{Eletrólitos, vitaminas e minerais}

Eletrólitos, vitaminas, macro e micronutrientes também podem ser adicionados à NP, mas geralmente só são utilizados quando a terapia durar mais que duas semanas (Oliveira et al., 2008). As vitaminas, em especial as hidrossolúveis, são perdidas rapidamente no estado catabólico e na anorexia, sendo que o animal não apresenta estoque suficiente desses nutrientes. Elas participam em várias etapas da utilização de energia como cofatores e o suporte nutricional acelera seu consumo. Deficiência de 
vitaminas do complexo $\mathrm{B}$, principalmente tiamina e riboflavina, favorecem o desenvolvimento da síndrome da realimentação, um distúrbio metabólico que se desenvolve no paciente anorético quando recebe alimentação, sendo potencialmente fatal (Campbell, 2007). Devido ao fato de que várias vitaminas do complexo B são sensíveis à luz, é recomendável proteger o recipiente que contém a solução com material que impeça a incidência de luz. Dose de $1,0 \mathrm{~mL}$ de solução de vitamina do complexo B por $100 \mathrm{kcal}$ de energia fornecida é suficiente para garantir níveis adequados de riboflavina e tiamina (Carciofi et al., 2009).

Fósforo, magnésio e potássio também estão implicados na síndrome da realimentação. Esses eletrólitos são perdidos durante a lise tecidual secundária à inanição e após a infusão de calorias ocorre captação celular desses elementos, baixando drasticamente seus níveis plasmáticos. Além disso, a glicose estimula secreção de insulina e aumenta a utilização de fósforo, de forma que a administração muito rápida de glicose em animais anoréticos favorece a hipofosfatemia. Para animais normocalêmicos, as soluções de NP devem conter entre 20 e $30 \mathrm{mEq} / \mathrm{L}$ de potássio. Caso o animal apresente hipocalemia, normalmente aumenta-se a dose para $40 \mathrm{mEq} / \mathrm{L}$, monitorando-se a resposta do paciente e realizando-se ajustes conforme a necessidade. Já em casos de hipercalemia esse eletrólito não deve ser adicionado à solução de NP e o acompanhamento deve ser diário, para avaliar corretamente o momento de iniciar a suplementação desse nutriente. As soluções também devem conter entre 10 e $20 \mathrm{mmol} / \mathrm{L}$ de fósforo e, em casos de hiperfosfatemia, é recomendável diminuir os aminoácidos, eletrólitos e lipídeos para reduzir a concentração de fosfatos (Carciofi et al., 2009).

A adição de micronutrientes à solução de NP somente se faz necessária em animais subnutridos ou caso o suporte nutricional seja feito por período superior a cinco dias. Os nutrientes mais comumente suplementados são zinco, manganês e cobre (Queau et al., 2011).

\section{Complicações da administração de NE e NP}

As complicações relacionadas à administração de NE e NP podem ser mecânicas, sépticas ou metabólicas. Complicações mecânicas incluem qualquer problema envolvendo o tubo ou o cateter, causando interrupção temporária ou permanente do fornecimento da nutrição, como trombose, deslocamento, vazamento, oclusão ou entupimento. Complicações sépticas são caracterizadas por inflamação local do cateter em animais com febre ou neutrofilia não relacionada à doença primária e cultura bacteriana positiva da ponta do cateter ou do sangue. Já as complicações metabólicas foram definidas como variáveis bioquímicas ou hematológicas comparadas com os valores de referência normais e classificadas com hiper (valores bioquímicos maiores que os de referência para a espécie) e como hipo (valores bioquímicos menores que os de referência para a espécie). Exemplos de possíveis complicações metabólicas incluem hipocalemia, hiperglicemia, hipomagnesemia, hipofosfatemia e lipemia (Queau et al., 2011, Liu et al., 2012).

A gravidade e os sinais clínicos decorrentes dessas complicações estão diretamente relacionados à técnica empregada para fornecimento da dieta. As complicações associadas com o uso de sonda naso-esofágicas mais comuns incluem obstrução, remoção da sonda pelo próprio animal, epífora, atraso no esvaziamento gástrico, aspiração, vômitos, diarreia, hipocalemia, moléstias nasais e faríngeas relacionadas à sua permanência prolongada. Com o uso de sonda esofágica as complicações associadas incluem infecção do campo operatório, edema de face por pressão exercida pela bandagem, esofagite, aspiração de alimento, obstrução das vias aéreas superiores, disfagia, vômito (com saída da sonda pela cavidade bucal) e gastrite. No entanto, essas complicações são incomuns e se associam ao erro no manejo da sonda e da ferida cirúrgica. $\mathrm{O}$ uso de sondas intestinais pode desenvolver complicações como oclusão do tubo, diarreia, vômitos, desconforto abdominal e peritonite. Esta última é a complicação mais preocupante e pode ocorrer devido ao extravasamento de alimento do local de inserção da sonda, provocado por deslocamento ou retirada prematura do tubo. Esse extravasamento também pode contribuir com o desenvolvimento de celulite ou infecção local (Brunetto et al., 2009, Chan, 2009). Complicações relacionadas com a NP incluem obstruções, septicemia, tromboflebite e vários distúrbios metabólicos. Dessas, a mais séria, porém incomum, é a septicemia. Para evitá-la os curativos do cateter devem ser trocados a cada 24 horas e o local de inserção avaliado quanto à presença de alguma alteração. A contaminação bacteriana da solução também deve ser 
considerada. As obstruções podem ser evitadas com o uso de cateteres de boa qualidade lavados com solução anticoagulante. Hiperglicemia e hiperlipemia são os distúrbios mais comuns. A hiperglicemia geralmente não necessita ser corrigida pela utilização de insulina, bastando diminuição da velocidade de infusão da glicose para reverter o quadro. A hiperlipidemia também pode ser corrigida diminuindo-se a concentração de lipídeos da solução infundida (Carciofi et al., 2009, Chan, 2009). Devido à captação de potássio que a glicose promove e, consequentemente, à redução desse eletrólito no sangue, a hipocalemia é uma complicação a ser considerada. A suplementação de potássio é de extrema importância. A monitoração frequente dos sinais vitais, das condições do cateter e a realização de exames bioquímicos permitem ao clínico antecipar e/ou diagnosticar precocemente várias complicações. Um método eficiente de evitar contaminações consiste em evitar desconexões desnecessárias do cateter, além da troca da bolsa de solução e todos os componentes do sistema de administração diariamente (Carciofi et al., 2009, Chan, 2009).

$\mathrm{O}$ risco de desenvolvimento de complicações sépticas é maior em cães que receberam NP periférica (veia safena) comparados com pacientes que receberam NP central (veia jugular). O sangue e o cateter de alguns cães acometidos por complicações sépticas foram cultivados e revelaram microorganismos como Escherichia coli, Serratia marcescens, Staphylococcus intermedius e Pseudomonas aeruginosa. A NP é efetiva no fornecimento das necessidades energéticas de cães em estado crítico e a maioria das complicações que acompanham essa técnica não afetam a sobrevivência, desde que o animal seja rigorosamente monitorado (Queau et al., 2011).

\section{Considerações finais}

A presente revisão de literatura demonstrou a importância e a contribuição do suporte nutricional para cães hospitalizados e que, dependendo das observações clínicas, existirão procedimentos diferentes para a reposição de perdas calóricas. A nutrição do animal durante o período de internação é tão importante quanto a dieta durante a vida. Sem o aporte de nutrientes e calorias necessárias para a manutenção das funções vitais e recuperação de injúrias, o animal poderá sucumbir aos efeitos deletérios da anorexia e do hipermetabolismo.

\section{Referências Bibliográficas}

Armstrong, P. J. \& Lippert, A. 1988. Selected aspects of enteral and parenteral nutritional support. Seminars in veterinary medicine and surgery (small animal).

Brunetto, M. A., Gomes, M. O. S., Andre, M. R., Teshima, E., Gonçalves, K. N. V., Pereira, G. T., Ferraudo, A. S. \& Carciofi, A. C. 2010. Effects of nutritional support on hospital outcome in dogs and cats. Journal of Veterinary Emergency and Critical Care, 20, 224-231.

Brunetto, M. A., Gomes, M. O. S., Nogueira, S. P. \& Carciofi, A. C. 2009. Suporte nutricional enteral no paciente crítico. Clínica Veterinária, 40-49.

Campbell, J. A., Jutkowitz, L. A., Santoro, K. A., Hauptman, J. G., Holahan, M. L. \& Brown, A. J. 2010. Continuous versus intermittent delivery of nutrition via nasoenteric feeding tubes in hospitalized canine and feline patients: 91 patients (2002-2007). Journal of Veterinary Emergency and Critical Care, 20, 232-236.

Campbell, S. J. 2007. Nutritional considerations for animals with pulmonary disease. Veterinary Clinics of North America: Small Animal Practice, 37, 989-1006.

Carciofi, A. C. 2008. Manejo nutricional do cão e do gato hospitalizado. In: UNESP (ed.) Apontamentos teóricos das disciplinas de clínica das doenças carenciais, endócrinas e metabólicas e de nutrição e alimentação de cães e gatos. Universsidade de São Paulo, Jaboticabal.

Carciofi, A. C., Brunetto, M. A., Gomes, M. O. S., Teshima, E. \& Jeremias, J. T. 2009. Suporte nutricional parenteral no paciente crítico. Clínica Veterinária, 52-60.

Chan, D. L. 2009. The inappetent hospitalised cat: clinical approach to maximising nutritional support. Journal of Feline medicine and Surgery, 11, 925-933.

Chan, D. L. \& Freeman, L. M. 2006. Nutrition in critical illness. Veterinary Clinics of North America: Small Animal Practice, 36, 12251241.

Chan, D. L., Freeman, L. M., Labato, M. A. \& Rush, J. E. 2002. Retrospective evaluation of partial parenteral nutrition in dogs and cats. Journal of Veterinary Internal Medicine, 16, 440-445. 
Codner, P. A. 2012. Enteral nutrition in the critically ill patient. Surgical Clinics of North America, 92, 1485-1501.

Cunningham, J. 2011. Tratado de fisiologia veterinária. Guanabara Koogan, Rio de Janeiro.

Dudrick, S. J. 2009. History of parenteral nutrition. Journal of the American College of Nutrition, 28, 243-251.

Fontoura, C. S. M., Cruz, D. O., Londero, L. G. \& Vieira, R. M. 2006. Avaliação nutricional de paciente crítico. Revista Brasileira de Terapia Intensiva, 18, 298-306.

González Domínguez, M. S., Vélez, C., Acevedo Naranjo, C. M. \& Ruíz Sierra, I. C. 2008. Nutrición parenteral post-quirúrgica en un paciente canino sometido a corrección de ruptura vesical. Reporte de un caso. Revista Colombiana de Ciencias Pecuarias, 21, 77-86.

Hekman, J. P., Karas, A. Z. \& Dreschel, N. A. 2012. Salivary cortisol concentrations and behavior in a population of healthy dogs hospitalized for elective procedures. Applied Animal Behaviour Science, 141, 149-157.

Holahan, M., Abood, S., Hauptman, J., Koenigsknecht, C. \& Brown, A. 2010. Intermittent and continuous enteral nutrition in critically ill dogs: a prospective randomized trial. Journal of Veterinary Internal Medicine, 24, 520-526.

Kang, Y., Lee, H.-S., Paik, N.-J., Kim, W.-S. \& Yang, M. 2010. Evaluation of enteral formulas for nutrition, health, and quality of life among stroke patients. Nutrition Research and Practice, 4, 393-399.

Kawasaki, N., Suzuki, Y., Nakayoshi, T., Hanyu, N., Nakao, M., Takeda, A., Furukawa, Y. \& Kashiwagi, H. 2009. Early postoperative enteral nutrition is useful for recovering gastrointestinal motility and maintaining the nutritional status. Surgery Today, 39, 225-230.

Lehninger, N. D. L. 2006. Principios de bioquímica. São Paulo.

Lewis, D. H., Chan, D. L., Pinheiro, D., ArmitageChan, E. \& Garden, O. A. 2012. The immunopathology of sepsis: Pathogen recognition, systemic inflammation, the compensatory anti-inflammatory response, and regulatory $\mathrm{T}$ cells. Journal of Veterinary Internal Medicine, 26, 457-482.

Liu, D. T., Brown, D. C. \& Silverstein, D. C. 2012. Early nutritional support is associated with decreased length of hospitalization in dogs with septic peritonitis: a retrospective study of 45 cases (2000-2009). Journal of Veterinary Emergency and Critical Care, 22, 453-459.

Mansfield, C. S., James, F. E., Steiner, J. M., Suchodolski, J. S., Robertson, I. D. \& Hosgood, G. 2011. A pilot study to assess tolerability of early enteral nutrition via esophagostomy tube feeding in dogs with severe acute pancreatitis. Journal of Veterinary Internal Medicine, 25, 419-425.

Nelson, R. W. \& Couto, C. G. 2015. Medicina interna de pequenos animais. Elsevier Editora, Amsterdan.

Nguyen, N. Q., Besanko, L. K., Burgstad, C., Bellon, M., Holloway, R. H., Chapman, M., Horowitz, M. \& Fraser, R. J. L. 2012. Delayed enteral feeding impairs intestinal carbohydrate absorption in critically ill patients. Critical Care Medicine, 40, 50-54.

Oliveira, J., Palhares, M. S. \& Veado, J. C. C. 2008. Nutrição clínica em animais hospitalizados: da estimulação do apetite à nutrição parenteral. Revista da FZVA, 15, 172185.

Queau, Y., Larsen, J. A., Kass, P. H., Glucksman, G. S. \& Fascetti, A. J. 2011. Factors associated with adverse outcomes during parenteral nutrition administration in dogs and cats. Journal of Veterinary Internal Medicine, 25, 446-452.

Rabelo, N. N., Cariús, C., Tallo, F. S. \& Lopes, R. D. 2012. Conduta nutricional no trauma para o clínico. Revissta Brasileira de Clinica Médica 10, 116-21.

Silva, N. E. O. F. 2009. Nutrição do intestino, imunidade intestinal e resistência a parasitas do intestino em cães. Faculdade de Medicina Veterinária. Universidade Técnica de Lisboa. Faculdade de Medicina Veterinária, Lisboa.

Walton, R. S., Wingfield, W. E., Ogilvie, G. K., Fettman, M. J. \& Matteson, V. L. 1996. Energy expenditure in 104 postoperative and traumatically injured dogs with indirect calorimetry. Journal of Veterinary Emergency and Critical Care, 6, 71-79.

Article History:

Received 10 April 2017

Accepted 6 June 2017

Available on line 8 August 2017

License information: This is an open-access article distributed under the terms of the Creative Commons Attribution License 4.0, which permits unrestricted use, distribution, and reproduction in any medium, provided the original work is properly cited. 